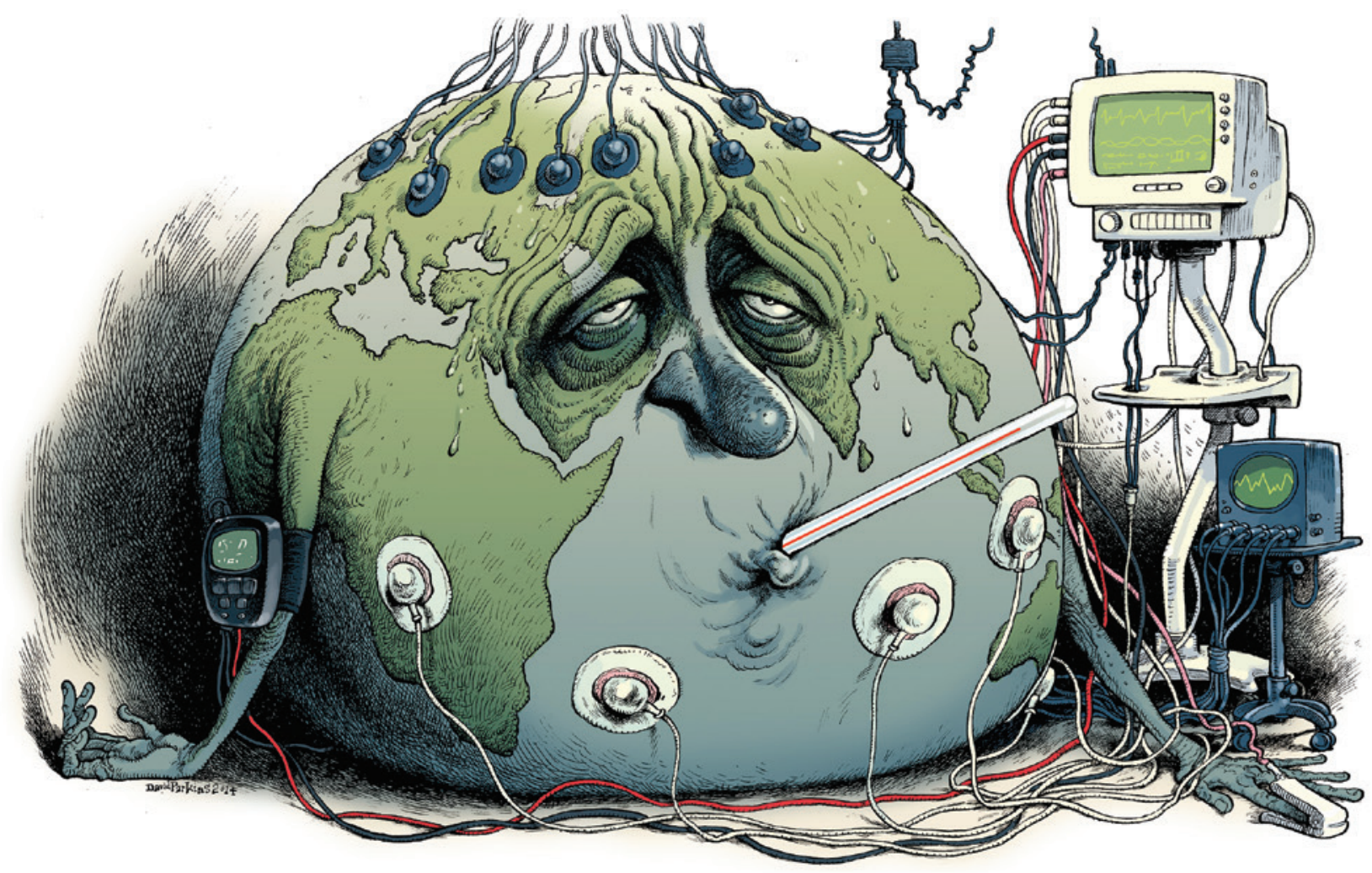

\title{
Ditch the $2^{\circ} \mathrm{C}$ warming goal
}

\section{Average global temperature is not a good indicator of planetary health. Track a range of vital signs instead, urge David G. Victor and Charles F. Kennel.}

$\mathrm{F}$ Tor nearly a decade, international diplomacy has focused on stopping global warming at $2{ }^{\circ} \mathrm{C}$ above preindustrial levels. This goal — bold and easy to grasp - has been accepted uncritically and has proved influential.

The emissions-mitigation report of the Fifth Assessment of the Intergovernmental Panel on Climate Change (IPCC) is framed to address this aim, as is nearly every policy plan to reduce carbon emissions - from California's to that of the European Union (EU). This month, diplomatic talks will resume to prepare an agreement ahead of a major climate summit in Paris in 2015; again, a $2^{\circ} \mathrm{C}$ warming limit is the focus.

Bold simplicity must now face reality. Politically and scientifically, the $2{ }^{\circ} \mathrm{C}$ goal is wrong-headed. Politically, it has allowed some governments to pretend that they are taking serious action to mitigate global warming, when in reality they have achieved almost nothing. Scientifically, there are better ways to measure the stress that humans are placing on the climate system than the growth of average global surface temperature — which has stalled since 1998 and is poorly coupled to entities that governments and companies can control directly ${ }^{1}$.

Failure to set scientifically meaningful goals makes it hard for scientists and politicians to explain how big investments in climate protection will deliver tangible results. Some of the backlash from 'denialists' is partly rooted in policy-makers' obsession with global temperatures that do not actually move in lockstep with the real dangers of climate change.

New goals are needed. It is time to track an array of planetary vital signs - such as changes in the ocean heat content - that are better rooted in the scientific understanding of climate drivers and risks. Targets must also be set in terms of the many individual gases emitted by human activities and policies to mitigate those emissions.

\section{OWN GOAL}

Actionable goals have proved difficult to articulate from the beginning of climatepolicy efforts. The 1992 United Nations Framework Convention on Climate Change (UNFCCC) expressed the aim as preventing "dangerous anthropogenic interference in the climate system". Efforts to clarify the meaning of 'dangerous' here have proved fruitless because science offers many different answers depending on which part of the climate system is under scrutiny, and each country has a different perspective ${ }^{2}$.

The 2009 and 2010 UNFCCC Conference of the Parties meetings, in Copenhagen and Cancun, Mexico, respectively, reframed the policy goal in more concrete terms: average global temperature. There was little scientific basis for the $2{ }^{\circ} \mathrm{C}$ figure that was adopted, but it offered a simple focal point and was familiar from earlier discussions, including those by the IPCC, EU and Group of 8 (G8) industrial countries ${ }^{3}$. At the time, the $2{ }^{\circ} \mathrm{C}$ goal sounded bold and perhaps feasible.

Since then, two nasty political problems have emerged. First, the goal is effectively unachievable ${ }^{4}$. Owing to continued failures to mitigate emissions globally, rising emissions are on track to blow through this limit eventually. To be sure, models show that it is just possible to make deep planet-wide cuts in emissions to meet the goal ${ }^{5}$. But those simulations make heroic assumptions - such as almost immediate global cooperation and widespread availability 
\& of technologies such as bioenergy carbon capture and storage methods that do not exist even in scale demonstration ${ }^{2}$.

Because it sounds firm and concerns future warming, the $2^{\circ} \mathrm{C}$ target has allowed politicians to pretend that they are organizing for action when, in fact, most have done 密 little. Pretending that they are chasing this unattainable goal has also allowed governments to ignore the need for massive adaptation to climate change.

Second, the $2{ }^{\circ} \mathrm{C}$ goal is impractical. It is related only probabilistically to emissions and policies, so it does not tell particular governments and people what to do. In other areas of international politics, goals have had a big effect when they have been translated into concrete, achievable actions ${ }^{6}$. For example, the eight Millennium Development Goals (MDGs) adopted by the United Nations in 2000 were effective when turned into 21 targets and 60 detailed indicators measurable, practical and connected to what governments, non-governmental and aid organizations and others could $\mathrm{do}^{7}$.

\section{TROUBLING PAUSE}

The scientific basis for the $2{ }^{\circ} \mathrm{C}$ goal is tenuous. The planet's average temperature has barely risen in the past 16 years (see 'Heat exchange'). But other measures show that radiative forcing - the amount by which accumulating greenhouse gases in the atmosphere are perturbing the planet's energy balance - is accelerating.

The Arctic, for example, has been warming rapidly. High-latitude climates are more sensitive than the planet as a whole. Amplifications in the Arctic might be causing extreme weather in middle latitudes ${ }^{9}$.

How could human stresses on the climate be rising faster even as global surface temperatures stay flat? The answer almost certainly lies in the oceans. The oceans are taking up $93 \%$ of the extra energy being added to the climate system, which is stoking sea-level rise and other climate impacts.

A single index of climate-change risk would be wonderful. Such a thing, however, cannot exist. Instead, a set of indicators is needed to gauge the varied stresses that humans are placing on the climate system and their possible impacts. Doctors call their basket of health indices vital signs. The same approach is needed for the climate.

The best indicator has been there all along: the concentrations of $\mathrm{CO}_{2}$ and the other greenhouse gases (or the change in radiative forcing caused by those gases). Such parameters are already well measured through a network of international monitoring stations. A global goal for average concentrations in 2030 or 2050 must be agreed on and translated into specific emissions and policy efforts, updated periodically, so that individual governments can see clearly how

\section{HEAT EXCHANGE}

Deep ocean waters have continued to become warmer despite global average temperature flattening off in the past 16 years.

0ิ

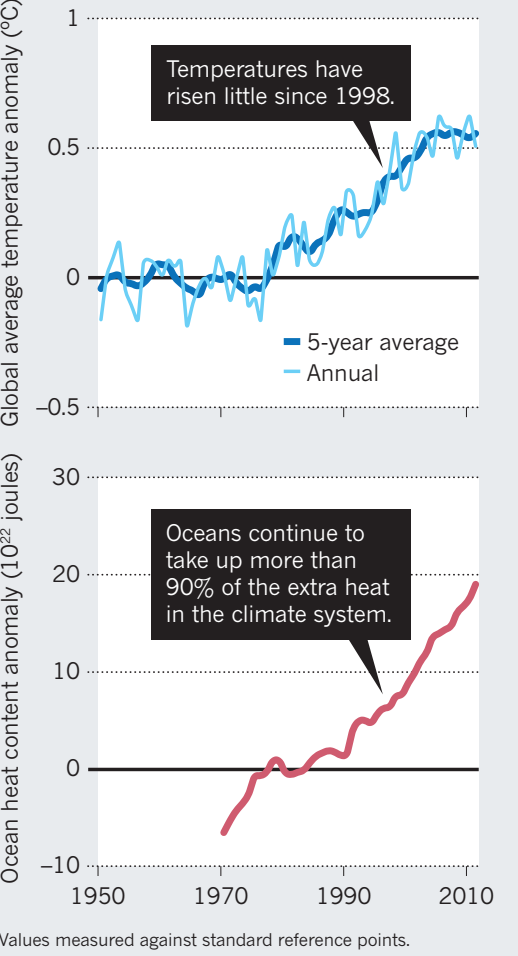

their actions add up to global outcomes.

Some pollutants that perturb the climate, such as methane or soot, have huge regional and local variations, and important uncertainties remain about the link between human emissions and measured concentrations. Policy initiatives are gaining momentum that would improve measurement and control of those warming agents. For example, the Climate and Clean Air Coalition is a group of countries focused on ways to cut emissions of short-lived climate pollutants.

Policy-makers should also track ocean heat content and high-latitude temperature. Because energy stored in the deep oceans will be released over decades or centuries, ocean heat content is a good proxy for the long-term risk to future generations and planetary-scale ecology. High-latitude temperatures, because they are so sensitive to shifts in climate and they drive many tangible harms, are also useful to include in the planetary vital signs ${ }^{9}$.

\section{CHART A PATH}

What is ultimately needed is a volatility index that measures the evolving risk from extreme events - so that global vital signs can be coupled to local information on what people care most about. A good start would be to track the total area during the year in which conditions stray by three standard deviations from the local and seasonal mean ${ }^{10}$.

The window of opportunity for improving goal-setting is open. This autumn, a big push on climate policy begins - with the aim of crafting a new global agreement by late 2015 at the UNFCCC's Conference of the Parties in Paris. Getting serious about climate change requires wrangling about the cost of emissions goals, sharing the burdens and drawing up international funding mechanisms. But diplomats must move beyond the $2{ }^{\circ} \mathrm{C}$ goal. Scientists must help them to understand why, and what should replace it.

New indicators will not be ready for the Paris meeting, but a path for designing them should be agreed there. Such a clear international mandate would spur research on indicators of planetary health, just as the United Nations' Millennium Summit on extreme poverty gave political momentum to the MDGs. The Paris agreement should call for an international technical conference on how to turn today's research measurements into tomorrow's planetary vital signs.

The public needs to understand what it is being asked to pay for. On this score, ' $\mathrm{CO}_{2}$ concentration' or 'ocean heat content' are not nearly effective as 'temperature' in conveying to the person in the street what is at risk. Yet patients have come to understand that doctors must track many vital signs - blood pressure, heart rate and body mass index to prevent illness and inform care. A similar strategy is now needed for the planet.

David G. Victor is professor of international relations at the School of International Relations and Pacific Studies, University of California, San Diego, La Jolla, California, USA. Charles F. Kennel is distinguished professor and director emeritus at the Scripps Institution of Oceanography, University of California, San Diego, La Jolla, California, USA. e-mail:david.victor@ucsd.edu

1. Balmaseda, M. A., Trenberth, K. E. \& Källén, E. Geophys. Res. Lett. 40, 1754-1759 (2013).

2. Victor, D. G. et al. in Climate Change 2014: Mitigation of Climate Change. Contribution of Working Group III to the Fifth Assessment Report of the Intergovernmental Panel on Climate Change (eds Edenhofer, O. et al.) (Cambridge Univ. Press, 2014).

3. Randalls, S. WIREs Clim. Change 1,598-605 (2010).

4. Victor, D. G. Global Warming Gridlock: Creating More Effective Strategies for Protecting the Planet (Cambridge Univ. Press, 2011).

5. Clarke, L. et al. in Climate Change 2014: Mitigation of Climate Change. Contribution of Working Group III to the Fifth Assessment Report of the Intergovernmental Panel on Climate Change (eds Edenhofer, O. et al.) (Cambridge Univ. Press, 2014).

6. Levy, M. A. in Institutions for the Earth: Sources of Effective International Environmental Protection (eds Hass, P. M., Keohane, R. O. \& Levy, M. A.) 75-132 (MIT Press, 1993).

7. Bourguignon, F. et al. in Equity and Growth in a Globalizing World 17-40 (eds Kanbur, R. \& Spence, M.) (World Bank, 2010).

8. Hansen, J., Kharecha, P. \& Sato M. Environ. Res. Lett. 8, 011006 (2013).

9. Cohen, J. et al. Nature Geosci. 7, 627-637 (2014)

10. Hansen, J., Sato, M. \& Ruedy, R. Proc. Natl Acad. Sci. USA 109, E24150-E2423 (2012). 